\title{
PERSONALITY IN SITUATIONS
}

Personality in Situations: Going Beyond the OCEAN and Introducing the Situation Five

\author{
Matthias Ziegler ${ }^{1}$, Kai T. Horstmann ${ }^{1}$, \& Johanna Ziegler \\ Humboldt-Universität zu Berlin, Germany \\ ${ }^{1}$ shared first authorship
}

This article is conditionally accepted for publication in the Journal

Psychological Assessment

Special Issue: Personality Assessment

\section{Corresponding Author:}

Kai T. Horstmann

horstmak@hu-berlin.de

Institute of Psychology, Dept. of Psychological Diagnostics

Rudower Chaussee 18

12489 Berlin

\section{Funding:}

This research was supported by Schuhfried GmbH, Hyrtlstraße 45, AT-2340 Mödling.

\section{Author Note:}

The data presented in this manuscript were also used in the Manual of the proprietary test, The Big Five Inventory of Personality in Occupational Situations (Ziegler, 2014). Furthermore, the scales presented here have been referenced in a published book chapter (Horstmann, Rauthmann, $\&$ Sherman, accepted).

\section{Public Significance Statement:}

This paper introduces the idea of situational perceptions as traits: The Situation Five. Based on this idea a questionnaire with a special focus on an occupational context measuring the general tendency of a person to perceive situations and personality at the same time is presented. 


\section{PERSONALITY IN SITUATIONS}

\section{Abstract}

We present the psychometric evaluation of a personality measure that assesses the Big Five and situation perception based on a newly developed taxonomy of situation characteristics. Following the lexical approach, more than 15,000 adjectives were extracted from an authoritative German dictionary. In a first exploratory study, 521 participants rated every-day situations on 300 adjectives selected as potential situation descriptors. Seven dimensions of situation perception were initially extracted. In a second study with $N=387$, five of these seven factors were confirmed: Outcome-Expectancy, Briskness, Cognitive Load, Psychological and Physical Load, and Lack of Stimuli, together referred to as the Situation Five. Finally, a measurement tool, the Big Five of Personality in Occupational Situations (B5PS), was constructed to assess the Big Five personality traits and the Situation Five simultaneously. We present evidence for the reliability, convergent and discriminant validity and predictive validity of the B5PS test scores. Our study highlights the relevance of situation perception as a trait and discusses their applicability in diverse contexts.

Keywords: Situation Perception; Personality Assessment; Big Five; Situation Five; Situation Characteristics; Situation Taxonomy; Situation(al) Judgement Test

\section{Public Significance Statement:}

This paper introduces the idea of situation perceptions as traits: The Situation Five. Based on this idea a questionnaire measuring the general tendency of a person to perceive situations and personality at the same time is presented. 


\section{PERSONALITY IN SITUATIONS}

\section{Personality in Situations: Going Beyond the OCEAN and Introducing the Situation Five}

It is widely accepted that the behavior of a person is influenced by internal aspects of the person, such as personality, but also by external factors such as aspects of the situation (Lewin, 1936; Mischel \& Shoda, 1995; Rauthmann, Sherman, \& Funder, 2015). Personality theories have been exhaustively examined, and numerous well-accepted taxonomies for the description of personality have been developed (e. g., the Big Five, Goldberg, 1990). Recently, the convergence of such models with pathological traits has been established (Thomas et al., 2013). Furthermore, scores derived from measures of personality were successfully linked to external criteria for example career success or subjective well-being (e.g., Barrick, Mount, \& Judge, 2001; E. \& Diener, 2009; Ozer \& Benet-Martínez, 2006; Schmidt \& Hunter, 1998). The situation, and especially the assessment of situational influences, has only recently received wider research attention (Horstmann, Rauthmann, \& Sherman, 2018). In recent years several taxonomies of situation (perception)s have been proposed, such as the DIAMONDS or CAPTION framework (Parrigon, Woo, Tay, \& Wang, 2017; Rauthmann et al., 2014), and it was shown that the measured perception of a situation is predictive for behavior in this situation (Sherman, Rauthmann, Brown, Serfass, \& Jones, 2015). Unfortunately, the development of measures incorporating both, situation perception and personality, is lacking behind. Considering the relevance of both constructs for assessment in clinical or organizational contexts, it seems important to show that a measure including both can be constructed. Most recently, Rockstuhl ${ }^{1}$ and colleagues (Rockstuhl, Ang, Ng, Lievens, \& Van Dyne, 2015) examined if the judgment of a situation and the response to the situation in situation judgment tests can be differentiated. Not

\footnotetext{
${ }^{1}$ We are thankful to a reviewer for directing us towards this study. Please note that we were unaware of this publication by the time we designed and analyzed the current study. Rockstuhl and colleagues' work therefore has not informed the data collection of the present work, yet their results support the necessity for this investigation, which is why we report their study here.
} 


\section{PERSONALITY IN SITUATIONS}

only was this the case, but they demonstrated convincingly how each response predicts unique variance in meaningful outcomes.

So far, no standardized inventory exists that allows assessing situation perception tendencies as well as behavioral responses to situations as indicators of personality at the same time. The current project was undertaken to close this gap. To this end a two-stage research project was conducted. Within the first stage a taxonomy of situation perception was developed using a lexical approach. In the second stage, an inventory measuring situation perception and personality simultaneously was constructed and evaluated.

\section{What Is a Situation?}

Rauthmann and colleagues (Rauthmann, Sherman, \& Funder, 2015) proposed that situation information can be found on three ordered levels: Situation Cues, situation Characteristics and situation Classes. Cues describe the elements that constitute a situation objectively, such as a table or coffee cup. Characteristics describe the psychological meaningful information of a situation. A situation could for example be pleasant, stressful, deceptive, or demanding. It is important to note that the same situation can be intellectually demanding for one person, whereas it can be rather dull for another. On an even more aggregated level, classes refer to different situations that are similar in either their situation characteristics or situation cues. Thus, situations that are perceived as intellectually stimulating as well as cognitively demanding could be subsumed in a class that could be labeled "Learning". Yet, no comprehensive taxonomy for situation classes has been developed thus far (Horstmann, Rauthmann, et al., 2018). Although situation classes or contexts have been used in previous research (e.g., Geukes, Nestler, Hutteman, Küfner, \& Back, 2016), their application does not allow a closer look at individual differences, as they assume that the psychological situation is similar for all persons within a 


\section{PERSONALITY IN SITUATIONS}

class (Horstmann, Ziegler, \& Ziegler, 2018). We thus argue that the most informative information on situations is that of situation characteristics, measured via situation perceptions.

What influences situation perception? Ziegler and Horstmann $(2016 ; 2015)$ described a model of situation perception which underlies the current work. The idea is that situation cues are processed by each individual in any given situation. This information processing is in part idiosyncratic (Rauthmann, 2012; Rauthmann, Sherman, \& Funder, 2015). That means that any situation judgment by a person is influenced by the situation judged, by the person that judges, and by their interaction. However, utilizing this person by situation-specific variance would require single case assessments, which is not feasible in many settings (Hogan, 2009; Ziegler \& Ziegler, 2015). Yet, as the proposed model suggests, underlying dimensions on the person-level exist that structure situation perceptions. They are the result of an individual information processing based on idiosyncratic patterns. In other words, we assume that the person-variance in situation perceptions can be measured reliably and is distinct from other psychological trait-like constructs such as the Big Five personality traits. It was empirically shown that situation perceptions on the person level allow explaining variance above and beyond established constructs (e.g., Rockstuhl et al., 2015; Sherman et al., 2015). Although the study by Rockstuhl and colleagues assessed situation perception on the person level to predict other outcomes, they did not employ a systematically derived and generalizable taxonomy of situations. On the other hand, Sherman and colleagues used an established framework to assess situation perception (the DIAMONDS by Rauthmann et al., 2014), but they did not use a fixed set of situations. Thus, their situation perception scores were not comparable across participants, as each participant experienced different situations. The current study combines these two approaches: First, a systematic taxonomy is developed for the description and assessment of situations. Second, a 


\section{PERSONALITY IN SITUATIONS}

questionnaire is developed that uses a fixed set of situations, thereby allowing to compare scores of situation perceptions between persons.

\section{The Importance of Situation Perception}

Situation perception has only recently been established as a construct on its own (Rauthmann, 2012). However, the principles of situation perception - namely the evaluation of external stimuli based on previous knowledge, personality, and current states - can be found in most areas of psychology. First, any study that contains ratings by participants about their “current situation" contains a situation judgment. For example, in Oud et al.'s study (Oud, Voelkle, \& Driver, 2017), participants had to state whether they were at home or at work. This judgment would most likely be based on their location, which is a situation cue. In some cases, though, people might work at home, which makes these judgments less valid. Ratings of participants' perceptions of work or home situations in general would thus be more beneficial. Second, appraisal theories of emotions are concerned with the perception of cues, their interpretation, and their resulting effect on affect (Horstmann \& Ziegler, 2018; Kuppens, 2009; Sander, Grandjean, \& Scherer, 2005). Measures of situation perception could shed light on this process, which ultimately makes situation perceptions also relevant for clinical psychology. Schwartz and Weinberger (1980) for example examined how different anxiety evolving situations influenced emotions. Similarly, Keller and Nesse (2006) examined how depression is affected differentially by varying situations. Other examples include the examination of anxiety in different naturally occurring situations (Chen et al., 2010) or even the use of mobile sensing that informs interventions for depressed patients (Burns et al., 2011). The interest in the "current situation" of a person is further reflected in the widely used SORC-model known from cognitive behavioral therapy (Kanfer \& Saslow, 1965). SORC stands for Stimulus, Organism, Reaction, 


\section{PERSONALITY IN SITUATIONS}

Consequence, and Stimulus can be understood as the perception of situation cues. Although all of the above studies shared a combined interest in the role of the situation in a clinical intervention, they also shared a lack of a systematic and generalizable way to assess the situation or even situation perception. As such, clinical research could benefit from a common framework that allows describing situations and assessing perceptions thereof. Moreover, the measure introduced here showcases the feasibility and advantages of measuring personality and situation perception in one instrument and being able to compare the obtained scores across participants.

Furthermore, situation judgment plays and important role in occupational psychology (Lievens, 2017; McDaniel, Morgeson, Finnegan, Campion, \& Braverman, 2001), and not only in the role of situational judgment tests. Predictive validity of ratings can be enhanced if these ratings are obtained in situations that are similar to later work environment (e.g., Shaffer \& Postlethwaite, 2012), and can thus also be applied to behavioral tasks in assessment centers or interviews. However, these tests usually rely on implicit assumptions about the similarity of situations designed for the hiring process and those encountered later. A systematic descriptive system of occupational situations could thus be used during the analysis of job requirements, which in turn could inform the situations used in the hiring process. Thus, the current project in its first stage also aimed at uncovering and structuring dimensions of situation characteristics.

\section{Situation Perception - Taxonomy and Assessment Tool}

To assess trait situation perception two conditions must be fulfilled: First, a taxonomy must exist that describes which dimensions situations can be described by, and second, an assessment tool must exist to measure intra-individual differences in situation perception.

Existing taxonomies of situation perception. Several taxonomies to describe situations have already been proposed (Horstmann, Rauthmann, et al., 2018; Rauthmann et al., 2014; Yang, 


\section{PERSONALITY IN SITUATIONS}

Read, \& Miller, 2006), and most of them focus on describing differences in situation characteristics. On the broadest level, these existing taxonomies can be classified into two groups. First, taxonomies that were constructed based on data, that is, bottom up (e.g., Rauthmann et al., 2014; Yang et al., 2006), second, taxonomies construed to explicitly reflect theoretical assumptions, that is, top-down (e.g., Brown, Neel, \& Sherman, 2015; Gerpott, Balliet, Columbus, Molho, \& de Vries, 2017). It is important to note that these different approaches to the development of situation perception taxonomies converge on a broader level (Horstmann, Rauthmann, et al., 2018; Rauthmann \& Horstmann, 2017), and that overarching dimensions of situation perception can be found (Rauthmann \& Sherman, 2018).

\section{Stage 1: Development of the Situation Five}

Thus, the first aim was to develop a taxonomy for situations as a vital component of a questionnaire assessing personality and situation perception at the same time.

\section{Study 1 - Development of the Situation Perception Taxonomy}

For the construction of the final assessment tool (see Study 3), the Big Five in Psychological Situations (B5PS), two different taxonomies and related scales had to be constructed and then combined. The first taxonomy was meant to portray dimensions of situation perception. The second taxonomy was meant to establish a broad facet structure of the Big Five. The construction of this latter taxonomy and the related scale is reported elsewhere (Cengia, Ziegler, \& Roberts, in prep.; MacCann, Danay, Ziegler, \& Roberts, 2011).

Lexical approach. The development of the situation perception taxonomy was grounded in the lexical approach. The lexical approach is most widely known with respect to the construction of the Big Five (John \& Srivastava, 1999). Its general assumption is that relevant and distinguishable features of an object are reflected in human language (Allport \& Odbert, 1936; 


\section{PERSONALITY IN SITUATIONS}

Deary, 2009), but there is also a general agreement that this also applies to characteristics of situations (e.g., Edwards \& Templeton, 2005; Parrigon, 2017; Van Heck, 1984, 1989; Yang et al., 2006). Thus, if a feature of a situation is perceived as relevant, a word should exist to describe it.

Sample. For the initial construction of the situation perception dimensions, we used a sample of $N=521$ participants, who were mainly students. Their mean age was $M=25.58$ $($ median $=24, S D=6.59), N=135$ were male $(25.91 \%), 379$ were female $(72.74 \%)$.

Materials and procedure. We first selected adjectives that could be applied to the description of situations. These adjectives were then used in a survey to rate perceptions of different situations. All studies presented throughout this manuscript were conducted according to standard ethical guidelines. All participants gave informed consent and agreed to the study procedure. An official IRB approval is not required in Germany.

Adjectives for situation ratings. To obtain adjectives that were suitable for the ratings of situations, we first extracted all 15,679 adjectives from the German spelling dictionary, the Duden (Dudenredaktion, 2006). These adjectives were then reduced to 300 by three independent raters. First, two raters examined the initial list of adjectives. Adjectives were excluded if they were generally not suitable to describe situations (e.g., scavenging, massless, careless, or uvular), were outdated or rarely used (e.g., haggard or earthy). Examples of items that were unknown to one of the two coders include the German vif (meaning lively), or adiabatisch. Across both raters, 228 adjectives were rated "unknown" by at least one of the raters, 4826 adjectives were rated as suitable by at least one of the raters, and 1934 adjectives were rated as suitable by both raters simultaneously. Removing the items that were marked as unknown, the raters achieved an 


\section{PERSONALITY IN SITUATIONS}

agreement of kappa $=.46 .^{2}$ All 4,826 adjectives that were rated as suitable by at least one rater were selected for the next step. Using an online dictionary, synonyms or hypernyms were identified and removed. For example, abenteuerlich (adventurous) has about 15 hypernyms. Two raters then removed all words that had a very similar meaning from this initial list, thereby reducing it to 2,720 words. These adjectives were then rated by a new rater using the same system as above, identifying 200 words as suitable. The third rater's goal was to reduce the number of items to a manageable size. To this end, he examined the list several times, iteratively. Finally, based on the ratings of each individual rater and the elimination of synonyms, all three raters discussed each of the 2,720 adjectives again and came up with a final list of 300 adjectives. Based on the ratings from and discussion among all three raters, these adjectives were not redundant, not out of use or barely known, and could be used to describe a situation. The final list of adjectives is available in the OSM.

Data collection. Participants completed an online questionnaire. First, they indicated their age, gender, and other demographic variables such as educational background. They subsequently had to answer the following question: "What did you do yesterday at 11a.m./4p.m./9p.m.?" (the respective time was randomly selected for each participant). After giving a brief verbal description of the situation, participants evaluated how well each adjective described their selected situation on 75 out of the 300 adjectives, on a 4-point Likert-type scale ranging from strong disagreement (1) to strong agreement (4). All in all, nine item blocks were created and randomly assigned to keep participant burden minimal. We used nine item blocks to ensure that each participant had some overlap in the adjectives used with participants that

\footnotetext{
${ }^{2}$ Note that this interrater agreement must not necessarily be high: For example, if one rater was simply not familiar with an adjective, but the other rater definitely knew that the adjective does not apply to situations the inter-rater agreement would decrease.
} 


\section{PERSONALITY IN SITUATIONS}

responded to another item block (e.g., block 1 includes items 1-75, and block 2 items 51-125, and so on), thus "linking" the item blocks to each other. Since we specified the missing adjectives in advance, the missing data (i.e., 225 adjectives that were not rated in a given block by one person) are missing completely at random (Rubin, 1976) and can therefore be imputed. We used an expectation maximization algorithm in SPSS to impute the missing data resulting in, thereby obtaining a full data set with $N=521$ participants and ratings across 300 adjectives. These ratings were analyzed using exploratory factor analysis.

Results of exploratory factor analyses (EFA). We used the psych-package (Revelle, 2014) in R (R Core Team, 2016) and Mplus 7.1 (Muthén \& Muthen, 2015) to analyze the data. To estimate the number of factors to extract, we examined the distribution of Eigenvalues, the minimum average partial test (MAP) and parallel analysis (1000 iterations). The first nine Eigenvalues were as follows: 8.99, 7.67, 5.79, 5.63, 5.09, 4.94, 4.24, 3.89, 3.64 (see Figure 1, Online Supplemental Material [OSM], for the first 40 Eigenvalues). The MAP-test suggested 34 factors and parallel analysis 23 . Based on content and, most importantly, interpretability of the factors and with the goal to extract broader, more heterogeneous constructs, we finally extracted seven oblique factors: Valence, Temporal environmental conditions, Cognitive Load, Psychological and Physical Load, Briskness, Lack of Stimuli, and Outcome-Expectancy. The items with the highest loadings are presented in Table A (OSM). Temporal environmental conditions, that is, the weather, did not have a psychological relevance for the final assessment tool and its items were therefore excluded from all further analyses. Another factor called Valence correlated highly with the remaining factors and was thus examined in later analyses as two higher order factors, named Burden and Vigor (see Figure 2, OSM).

\section{Study 2 - Replication in an Independent Sample}




\section{PERSONALITY IN SITUATIONS}

The aim of Study 2 was to replicate and test the individual factors established in Study 1 in an independent sample and obtain scales with a balanced number of items for each factor.

Sample. The sample consisted of $N=387$ participants chosen to representatively match the German speaking population. Their mean age was $45.59($ median $=44, S D=17.49), N=197$ participants were female $(50.90 \%)$.

Materials and procedure. Participants were invited to a laboratory and first provided information on demographic variables (age, gender, and level of education). Participants were required to name a situation from the previous day ("What did you do yesterday at 11 am./4p.m./9p.m.?") and the time was randomly chosen for each participant. Afterwards, each participant evaluated this situation on the same 4-point Likert-type scale used in Study 1. All in all, 59 adjectives from Study 1 were selected based on their factor loadings in the exploratory factor analyses and interpretability. Selection criteria were a balanced representation of each dimension as well as a broad coverage of the adjectives used. Moreover, item difficulties and loading sizes were considered. For example, items that had lower loadings, but extreme item difficulties were not removed to obtain a measure that is able to differentiate between persons with different trait levels. In some cases, adjectives were replaced by more colloquial alternatives to obtain higher discriminant validity of the factors. Examples of this include inauspicious (replaced with burdensome), barren (replaced with depressing), delightful (replaced with full of expectation), professional (replaced with productive and prolific). Furthermore, additional items were added in Study 2 to obtain an almost balanced number of items for each factor.

A confirmatory factor analysis was conducted for each measurement model of each of the initial six dimensions (without temporal environmental conditions). The factor Valence correlated highly with all other factors and was thus modeled as a higher order factor. 


\section{PERSONALITY IN SITUATIONS}

Five factors remained after this initial analysis. Some items were additionally deleted during the CFA, so that finally 48 adjectives remained. Selection was again based on loadings, item difficulties, and prototypicality for the specific factor (Ziegler, 2014a). The selected adjectives are displayed in Table A (OSM).

Results of confirmatory factor analysis (CFA). We first computed the CFAs as planned and subsequently added exploratory analyses of higher order factors.

Measurement models. Table 1 shows the results for each of the five measurement models. Based on the criteria for model fit by $\mathrm{Hu}$ and Bentler (1999), each model has an excellent fit, meeting the requirements for the CFI, RMSEA, and SRMR.

The final dimensions are Outcome-Expectancy, Briskness, Psychological and Physical Load, Lack of Stimuli, and Cognitive Load. Combined, we refer to them as the Situation Five.

Higher order factors. Additionally, and in an exploratory manner, we estimated a higher order factor model of the Situation Five. To this end, we computed item parcels containing 2-3 items. The items were assigned to their parcels based on the loading in an exploratory factor analysis (Little, Cunningham, Shahar, \& Widaman, 2002). This approach allowed estimating the full model while keeping the number of participants reasonably low. This model described the covariances of the Situation Five reasonably well (Figure 2, OSM). It had an acceptable model fit $\left(\chi^{2}=530.84, d f=86, p<.001, C F I=.89, R M S E A=.12, S R M R=.13\right.$, estimator: MLR $)$ We also ran an exploratory structural equation model (ESEM) ${ }^{3}$. It also had an acceptable model fit $\left(\chi^{2}=17.27, d f=40, p<.001, R M S R=.015\right.$, estimator: ML). Detailed results can be found in the OSF repository (osf.io/ys4j8).

\section{Discussion Studies 1 and 2 - Development of a Situation Taxonomy}

\footnotetext{
3 We are thankful for an anonymous reviewer for suggesting analyzing data additionally using ESEMs.
} 


\section{PERSONALITY IN SITUATIONS}

In the first two studies, we reported the development of a taxonomy for situation characteristics of everyday situations, the Situation Five. The five dimensions are OutcomeExpectancy (adjectives include "professional", "confident", "promising results"), Briskness (e.g., “vivid", “enchanting”, "lively”), Psychological and Physical Load (e.g., "irksome”, “woebegone", "tense”), Lack of Stimuli (e.g., "boring”, "barren”, “dull”), and Cognitive Load (e.g., "mind-wracking”, “demanding”, "excruciating”).

Despite the fact that some adjectives were added after the initial exploratory study (Study 1), the results of the confirmatory analyses showed that these adjectives were useful to capture the psychologically salient aspects of situations. Four out of five confirmatory models computed showed acceptable model fit. One exception, though, was the model of Cognitive Load: Four adjectives ("geistig stimulierend" [mentally stimulating], "herausfordernd" [challenging, demanding], "geistig anregend" [mentally inspiring], and "anspruchsvoll” [demanding, challenging]) had correlated residuals, possibly due to their shared content of 'cognitive stimulation'. This shared variance was therefore modeled in a bi-factor. Differences between the models of Study 1 and Study 2 were small, although some adjectives were changed and the student sample (Study 1) was replaced with a representative sample (Study 2).

The five dimensions of situation perception fit nicely into other existing taxonomies of situation characteristics (Horstmann, Rauthmann, et al., 2018) and thereby broaden and extend the nomological net of situation perception. Horstmann and Ziegler (2018) presented evidence

that these dimensions are meaningfully related to the DIAMONDS (Rauthmann et al., 2014), and explain variance in positive and negative affect within a given situation.

The most prominent other recent situation taxonomy that examined the structure of situations in a lexical approach is the CAPTION taxonomy by Parrigon and colleagues (Parrigon 


\section{PERSONALITY IN SITUATIONS}

et al., 2017). The authors identified seven situation dimensions: Complexity, Adversity, Positive Valence, Typicality, Importance, Humor, Negative Valence. As Horstmann and colleagues argued, these dimensions fit reasonably well to the five dimensions extracted in the current study (Horstmann, Rauthmann, et al., 2018; Rauthmann \& Horstmann, 2017; Rauthmann \& Sherman, 2018). Negative Valence corresponds to Psychological and Physical Load, Adversity to Cognitive Load, Importance to Outcome-Expectancy, Positive Valence and Humor to Briskness, and Typicality to Lack of Stimuli. Especially these two last dimensions - Typicality and Lack of Stimuli - were so far only identified when using a lexical approach, thus lending further credibility to the current findings.

Furthermore, the Situation Five were shown to have two higher order factors of situation perception, which we named Burden (loading on Psychological and Physical Load, Cognitive Load, and Lack of Stimuli), and Vigor (loading on Outcome-Expectancy and Briskness). Although the model fit of this model did not meet the requirements set by $\mathrm{Hu}$ and Bentler (1999), it is very similar to the fit presented by Rauthmann and Sherman (2016) for a CFA model of the DIAMONDS. These factors may represent positive and negative valence. Even though it is likely that higher order dimensions of situation perception exist (Horstmann, Rauthmann, et al., 2018; Rauthmann \& Sherman, 2018), the two dimensions presented here have to be replicated and examined in more detail before they can be clearly interpreted. We will therefore focus on the Situation Five domain level in the current article.

\section{Stage 2 - Development and Validation of the B5PS}

The objective in this stage was to develop a questionnaire that measures the Situation Five as traits as well as the Big Five personality traits. The decision to measure situation perceptions as traits was due to a specific criticism often brought forward against situation research, namely 


\section{PERSONALITY IN SITUATIONS}

that the prediction of future behavior with measures of state situation perception (i.e., perception of individual situations) is difficult. Hogan (2009) correctly stated that predicting behavior from one situation experience would lead to fruitless point predictions: One could only predict behavior of a person when both the person as well as the future situation are known. However, it is of course nearly impossible to predict how a person will perceive a future situation. In situ situation perceptions are vitally important for understanding how and when a situation will influence behavior, that is, for the explanation of behavior; yet they are less useful for the prediction of behavior in future unknown situations. We therefore argue that the general tendency of a person to perceive certain situations is relevant for the prediction of future behavior. As pointed out above, showing that situation perceptions can be measured like personality traits would have implications for all fields of psychology, especially organizational and clinical where the prediction or malleability of behavior is often focused.

\section{Comparison of Trait Situation Experiences}

The existing tools for the assessment of situation perception often measured situation perception of a participant by asking how a randomly selected situation was perceived, either by using an experience sampling design or by asking something along the lines of "how did you perceive the situation you were in yesterday at 12 a.m.?”. This is a valid approach for the construction of a situation taxonomy, yet it is problematic when scores of situation experiences should be compared between participants (Lievens, 2017). For example, it is likely that participants will select situations according to their preferences (Rauthmann, Sherman, Nave, \& Funder, 2015) and thereby report a biased set of situations: It is, on average, more likely that an extraverted person will experience more situations that are perceived as, for example, sociable. This can be either due to situational selection or situational construal. Thus, as long as the 


\section{PERSONALITY IN SITUATIONS}

situations are not fixed, scores on their perceptions are hard to compare. Being able to measure situation perception as a trait would eliminate this limitation.

\section{The B5PS and the ABC of Test Construction}

Whenever a new psychometric assessment tool (e.g., questionnaire, test, observation) is developed, some background information on this measure should be provided. Ziegler (2014b) presented a framework for this purpose, which can briefly be summarized with three questions:
A) What is the construct being measured?
B) What is the intended use of the measure?
C) What is the targeted population?

The answer to the first question requires that the construct is extensively described and integrated into a nomological net. This integration can happen on two levels: Either by linking it to theoretically relevant other constructs, or by providing empirical evidence for the relation to other constructs. Second, the intended use of the measure is important, since not every measure can or should be applied in all contexts. Some measures may be more relevant for empirical research (e.g., short scales), whereas other measures may be more relevant for an applied context. Whatever the intended purpose, sufficient empirical support should be provided that shows the applicability of a measure in its intended context. Third, the targeted population has to be clearly stated. A test that has been developed for one population is not necessarily applicable to another population.

With regard to the most recent situation taxonomies and their assessment tools, Horstmann and colleagues (Horstmann, Ziegler, et al., 2018) provided answers to these three questions. Measures of such taxonomies usually focused on A) the measurement of perceived state situation characteristics of random, everyday situations, B) the use of situation measures to predict in situ 


\section{PERSONALITY IN SITUATIONS}

behavior, and C) the assessment of every-day situations, judged by a population of normal (i.e., non-clinical) participants. With the B5PS, we present a measurement tool that assesses situation perception and personality simultaneously as traits, is therefore applicable in an applied context (with a focus on personnel selection and occupational health) and can be used for all people representative of the German working population. On a more abstract level, we demonstrate a principle which can also be adopted in clinical, educational, or other assessment settings.

We first describe the development of a new questionnaire to assess Big Five personality traits. We then describe how fixed situations were generated so that the Situation Five can be assessed on the same set of situations for each participant. Finally, the integration of situation and personality measures will be described.

Development of personality scales. The personality dimensions were taken from another study (Ziegler et al., in prep.). Based on items from the International Personality Item Pool (IPIP, 2015), Ziegler and colleagues constructed scales that measure the Big Five Openness, Conscientiousness, Extraversion, Agreeableness, and Neuroticism. Each of the domains has 7 to 9 facets, 42 all together, and each facet is measured with 5 items each. In a first step, the facet structure was derived from a sample of 726 US college students (MacCann, Danay, Ziegler, \& Roberts, 2011). In a second step, the items were translated into German and the facet structure as well as measurement invariance with the US sample was confirmed in an online sample of $N=$ 387 (Ziegler et al., in prep.).

Development of Situation Vignettes. The comparison of inter-individual differences in situation perception is only possible if the participants perceive the same or very similar situations. As a remedy, brief descriptions of hypothetical, work-related situations were therefore created, so called situation vignettes. We focused on work-related situations for several reasons: 


\section{PERSONALITY IN SITUATIONS}

First, similar to the argument made later by Rockstuhl and colleagues (2015), we sought to develop a tool that can be used in the applied context of situation selection and prediction of later behavior. Second, and despite the relevance for clinical psychology, the necessary samples that are relevant for a clinical scale are harder to obtain in sufficient quantity. Nevertheless, the principles presented here could also be applied to a clinical setting and should therefore be understood as a proof of concept.

For the construction of the situation vignettes, sixteen human resource managers were interviewed, asking them about typical situations within occupational settings. The resulting situations were re-framed so that they were brief (one or two sentences), unambiguous, and would relate well to one of the five dimensions of situation perception. The last point stresses that only certain behaviors are possible in certain situations, as postulated by the trait activation theory (Tett \& Burnett, 2003; Tett \& Guterman, 2000). It was also ensured that the vignettes allow a certain range of behavior: A fictional situation should not prompt the participant directly towards the "most appropriate" behavior in that situation, or it should not restrict the behavioral response options too much. Overall, 211 different situation vignettes were created. Each of the situation vignettes was expected to tap only one of the five dimensions of situation perception.

Integration of Big Five and Situation Five. To measure the Big Five and the Situation Five simultaneously, both were combined using an approach similar to a situation judgment task. The general idea is to present a brief description of a situation. Participants are required to first make a statement about their perception of this hypothetical situation and subsequently indicate how they would behave in it. For the B5PS, 211 of such items were constructed with one item for situation perception and one item for personality per vignette, resulting in 211 items for situation perception and 211 items for personality. 


\section{PERSONALITY IN SITUATIONS}

Item construction for the B5PS. The 211 items capturing the Situation Five were created based on the adjectives identified as markers in the previous two studies. Each adjective was used to complete the sentence: "I perceive the situation as ...". We adapted personality items marking the 42 facets previously identified.

\section{Method}

Sample and procedure. The final version of the questionnaire was applied to a representative sample of the German, Austrian, and Swiss population. The sample consisted of 173 women (43\%) and 225 men (57\%), ranging from 17 to 69 years. The mean age was 42.03 years $(S D=13.91)$. The data were collected in a controlled environment in the laboratories of Schuhfried GmbH in Mödling, Austria.

Materials. Participants responded to the final version of the B5PS. This included the 211 situation vignettes, for example "You just had your annual appraisal interview with your manager, in which you received a lot of detailed feedback. "In a first step, participants are required to rate how they would perceive such a situation, such as "I perceive this situation as challenging" (the last word/phrase is always the adjective identified in Studies 1 and 2). Subsequently, participants indicated how they would behave in this situation: "I reflect on the feedback". Responses were given on a 6-point Likert-type scale ( 1 = "strong disagreement" to 6 $=$ "strong agreement"). Each Big Five was combined with each Situation Five in a total of eight to ten vignettes, resulting in an overall total of 211 situation vignettes.

Data analysis. All data were analyzed using the lavaan package (Rosseel, 2015) in R. First, confirmatory factor analyses were computed for each measurement model of the Situation Five as well as each measurement model of the Big Five facets separately. For the Big Five, we tested measurement models for each domain using factor scores of the facets as indicators. Several 


\section{PERSONALITY IN SITUATIONS}

models were then tested for the complete Big Five model, including all domains: The first reflects the assumption underlying all Varimax rotated Big Five analyses. Consequently, a model with uncorrelated domains was tested (Costa \& McCrae, 1995; Goldberg, 1990). The second model allows correlated Big Five factors and is more in line with findings attesting correlations between Big Five scores (Mount, Barrick, Scullen, \& Rounds, 2005). Finally, we tested a model, which is based on research trying to explore the nature of the Big Five score intercorrelations. By now there is a body of research, both correlation- and experiment-based, that supports the notion that covariance between the Big Five domain scores is due to social desirability (Bäckström, 2007; Bäckström, Björklund, \& Larsson, 2009; Biderman, Nguyen, Cunningham, \& Ghorbani, 2011; Klehe et al., 2012; Oshio, Abe, Cutrone, \& Gosling, 2014; Schmit \& Ryan, 1993; Ziegler \& Buehner, 2009). Following this research, an additional bi-factor, reflecting social desirable responding, was added to the first model with uncorrelated personality domains. In this model, all other factors are controlled for this common variance.

With regard to model fit, personality structure models typically fail to reach the standards formulated by $\mathrm{Hu}$ and Bentler (1999) because of substantially lower loadings (Heene, Hilbert, Draxler, Ziegler, \& Bühner, 2011). Hopwood and Donellan (2010) analyzed several questionnaires and reported CFIs between .65 and .79 and RMSEAs between .09 and .13 . These values have been used by other researchers as references (Thalmayer \& Saucier, 2014). We will also do this, at the same time following advice to explore sources of misfit (Greiff \& Heene, 2017). Using the same procedure as in Study 2, we computed item-parcels for each of the Situation Five measurement models. Using these item-parcels, we examined the higher-order structure of the Situation Five.

\section{Results.}




\section{PERSONALITY IN SITUATIONS}

Confirmatory factor analyses - Situation Five. The results of the confirmatory factor analyses are displayed in Table 1, lower half. The models for the Situation Five showed mediocre model fit. The RMSEA values ranged from .067 to .100. The CFI values were low, especially compared to the values of the Big Five. However, CFI values reflect how much unique (error) variance remains unexplained in each item. Since the Situation Five items - and any measure of situation characteristics - capture the perception of a specific situation (i.e., the vignette), some of this variance must be specific (idiosyncratic) and therefore unexplainable by the trait situation perception. This is also why correlated residuals in the measurement models of the Situation Five which would improve model fit are scarce and mainly due to using the same adjective $^{4}$. In the end, we refrained from altering the models.

For the complete model of the Situation Five, we used item-parcels as indicators as described above (Figure 3, OSM). It had a reasonable model fit, $\chi^{2}=460.82, d f=86, p<.001$, $\mathrm{CFI}=.91, \mathrm{RMSEA}=.10[90 \% \mathrm{CI}: .10-.11], \mathrm{SRMR}=.16$. Two higher order factors were again found: The first called Vigor, loading on Briskness and Outcome-Expectancy, and the second called Burden, loading on Cognitive Load, Lack of Stimuli, and Psychological and Physical Load. However, due to the exploratory nature of these additional analyses, these higher order factors must be interpreted cautiously. Again, we also ran an exploratory structural equation model which yielded an acceptable model fit $\left(\chi^{2}=15.74, d f=40, p<.001, R M S R=.014\right.$, estimator: ML). Detailed results can be found in the OSF repository. These model fits are similar to the fits of the model in Study 1 and comparable to model fits of other assessment tools of situation characteristics (e.g., Brown et al., 2015; Rauthmann \& Sherman, 2016).

\footnotetext{
${ }^{4}$ In fact, when running these analyses in Mplus, no modification indices could be obtained for these models. However, lavaan still returned modification indices that could theoretically have been used to improve these models.
} 


\section{PERSONALITY IN SITUATIONS}

Confirmatory factor analyses - Big Five. The factor structure of each of the Big Five domains that were based on the factors scores of the underlying facets could be confirmed (Table 1), and all models showed a good model fit (see OSM, Table C, and reliabilities, OSM, Table D). The CFI ranged from .88 to .96 , and the SRMR from .05 to .06).

We tested three different theoretically plausible models for the structure of the Big Five personality traits. The first model, which assumed uncorrelated factors, had the worst model fit $\left(\chi^{2}=3,616.40, d f=815, \mathrm{RMSEA}=.093[.090-.096], \mathrm{CFI}=.54, \mathrm{SRMR}=.23\right)$. The second model, which allowed correlated factors, had a slightly better model fit $\left(\chi^{2}=2,669.75, d f=805\right.$, RMSEA $=.076[.073-.079], \mathrm{CFI}=.69, \mathrm{SRMR}=.09)$. The model that assumed a bi-factor structure fitted best, even though the CFI was still comparatively low: $\chi^{2}=2,273.03, d f=773$, $\mathrm{RMSEA}=.07[.067-.073], \mathrm{CFI}=.76, \mathrm{SRMR}=.08$. However, as explained above, this is typical for structural models of personality. In fact, the values found here can be regarded as good compared to the values reported by Hopwood and Donellan (2010). We therefore conclude that the bi-factor model describes the Big Five factor structure best. Similar to the Situation Five, we also ran an ESEM. Model fit was acceptable $(\mathrm{RMSR}=.05)$. Out of the 42 facet scores, nine had substantial cross-loadings, most likely due to not modeling social desirable responding.

\section{Reliability}

Reliability estimates reported for the scores of a measurement tool should depend on its intended use (Ziegler, 2014b). If a test score is supposed to be used for status assessments (i.e., the current state of the person), an estimate of internal consistency or other point-estimates of reliability (e.g., split-half or parallel-test reliability) are warranted, whereas a prediction of future outcomes requires the presentation of test-retest-reliability estimate. For the B5PS scores, we present Cronbach's alpha, McDonald's Omega, as well as the test-retest reliability estimates. 


\section{PERSONALITY IN SITUATIONS}

Sample and procedure. Cronbach's alpha and McDonald's Omega were estimated based on the norm sample of the B5PS $(N=398)$ described above. For the test-retest-reliability, $N=96$ participants completed the B5PS a second time $(\sim 65 \%$ return rate of questionnaires in second wave; time between measurement occasions: $M=5.7$ months, $S D_{\text {interval }}=1$ month, mean age of this subsample $=48.11$ years, $S D_{\text {age }}=15.9$ years, $40.6 \%$ male). The data-acquisition procedure of the norm-sample is described above.

Results. Results of the reliability analyses are displayed in Table F, OSM. Estimates for the internal consistencies of the Situation Five scores and the Big Five personality scale scores are very good, and so are factor reliabilities McDonald's Omega (alpha: .85 to .91, and omega: .65 to .96). The estimates for the 6-months test-retest reliabilities are also sufficient and range from $r$ $=.58$ (Lack of Stimuli and Cognitive Load) to $r=.75$ (Outcome-Expectancy). The estimates for internal consistencies of the Big Five scores are slightly lower compared to the Situation Five scores (ranging from .72 to .92 for alpha, and for omega from .66 to .86). However, the testretest reliabilities were higher compared to the Situation Five, ranging from $r=.63$ to $r=.85$.

\section{Validity}

Next to factorial validity, we will present evidence supporting the convergent and discriminant validity, as well as test-criterion correlations for the Big Five and the Situation Five test score interpretations.

Sample and procedure. The sample used for the validation studies is the norm-sample of the questionnaire $(N=398)$. Participants did not only respond to the B5PS, but additional questionnaires were also administered for the purpose of validation.

Big Five. The Big Five Structure Inventory (Big Five Struktur Inventar, BFSI, Arendasy, 2011) was used to obtain measures for convergent (Big Five) and discriminant (Situation Five) 


\section{PERSONALITY IN SITUATIONS}

validity. The BFSI uses 300 adjectives and short sentences modeling the same facets and domains suggested by Costa and McCrae (1995). Test scores are estimated using item response theory. Participants were required to rate the items on a four-point Likert-type scale ( 1 = "strong disagreement" to 4 = "strong agreement").

Work-Engagement. Work-engagement was assessed using the Utrecht-Work-Engagement scale (Seppälä et al., 2009), which assesses satisfaction with work based on one overall score and three facets (vigor, dedication, and absorption). Each facet is measured with 3 items using a seven-point frequency scale ranging from $0=$ "never" to $7=$ "always". Work-engagement shows a mediocre stability over an extended period of time (Mauno, Kinnunen, \& Ruokolainen, 2007; Seppälä et al., 2009), and it is reasonable to assume that its scores are influenced by the current context or the perception thereof. It is further related to perceived job-resources (Schaufeli \& Bakker, 2004). High work-engagement is "assumed to be the positive antipode of burnout" (Schaufeli \& Bakker, 2004, p. 294). Thus, the ability to predict work-engagement is not only relevant from an occupational perspective, but also from a clinical perspective, for example in burnout-prevention.

B5PS factor scores. For all subsequent regression and correlation analyses, we used the factor scores of the Big Five and Situation Five from the B5PS. The factor scores are computed based on the final structural models of Study 3. We used multiple linear regressions to predict all UWES scores (including the total composite score) with the Situation Five and the Big Five scores to investigate test-criterion correlations (concurrent validity).

\section{Results.}

Convergent and discriminant validity. Table E (OSM) presents the bivariate correlations between the Big Five and Situation Five, both assessed with the B5PS. The correlations among 


\section{PERSONALITY IN SITUATIONS}

the Big Five were moderate (the highest between Conscientiousness and Emotional Stability, $r=$ -.44). The correlations between the Situation Five were somewhat higher (up to $r=.70$ between Briskness and of Outcome-Expectancy), which was reflected in their shared higher order factor.

The correlations between the Big Five and Situation Five scores, as measured with the B5PS, and the Big Five scores from the BFSI are displayed in Table 2. The Situation Five scores correlated weakly to moderately with the Big Five scores from the BFSI. The highest correlation was between Emotional Stability and Psychological and Physical Load $(r=-.46)$. Overall, Outcome-Expectancy correlated highest with the Big Five scores $(r=.15$ to .43 , whereas Lack of Stimuli and Cognitive Load correlated lowest with the Big Five scores $(r=-.08$ to -.25 , and $r=$ .04 to 24, respectively). Briskness and Psychological and Physical Load correlated weak to moderately with the Big Five scores ( $r=.13$ to .31 and $r=-.46$ to -.06 , respectively).

The Big Five scores (B5PS) correlated highest with the corresponding personality trait score from the BFSI (see diagonal in the lower half of Table 2). Two convergent correlations were moderate (Conscientiousness, $r=.28$, and Agreeableness, $r=.28$ ), yet none of the other correlations of Conscientiousness and Agreeableness was higher. Correlations with other personality traits were small to moderate, indicating discriminant validity.

Test-criterion correlations - UWES. We predicted the overall UWES total score and its three facet scores (dedication, absorption, and vigor) using the Big Five scores assessed with the B5PS in a first block and the Situation Five scores in a second block within four separate hierarchical regression analyses. Since the UWES subscales were highly correlated ( $r$ Vigor.Dedication $=.78, r_{\text {Vigor.Absorpion }}=.79$, and $\left.r_{\text {Dedication.Absorption }}=.85\right)$, we also computed the UWES total score. The results of these analyses are displayed in Table G, OSM (for bivariate correlations with UWES and other outcome variables, see Table B, OSM). The Big Five scores explained only 


\section{PERSONALITY IN SITUATIONS}

little variance in all of the UWES scores. However, adding the Situation Five significantly increased the explained variance in all cases. Between $17.11 \%$ (Dedication) and 25.23\% (Vigor) could be explained using the Situation Five and the Big Five scores combined.

\section{Discussion - Study 3}

Factor structure. The structure of the Big Five items, facets, and domains showed a very good model fit. It has to be noted, though, that starting at domain level, models were fit to the factor scores from the facet models, not the individual items due to the restricted sample size.

For the measurement models of the Situation Five scores, the model fit was not perfect, and if judged by conventional levels that are for example applied to intelligence tests $(\mathrm{Hu} \&$ Bentler, 1999), in some cases unsatisfactory. However, as we have already mentioned above, an even lower model fit than in personality measures had to be expected in measures of situation perception (Horstmann, Ziegler, et al., 2018). As explained, this is due to the unique variance that can be attributed to the unique situation and thus a situation by person interaction resulting in idiosyncratic variance that is present in each item. It is common that the CFI is lower in models of situation perception due to this situation (vignette)-specific variance, which cannot be explained by the general situation perception of a person. We furthermore consider the high construct reliabilities as evidence for the cross-situation consistency of these factors.

Reliability. Reliability estimates of all scores were satisfying. The internal consistency and construct reliability estimates were very high across all ten scale scores. The test-retest reliability estimates for the Big Five scores (with the exception of Agreeableness: $r=.63$ ) were higher than the test-retest reliability estimates for the Situation Five scores. There are two possible explanations for this: First, the trait situation perception may change more across six months than trait personality, indicating that it is in itself a more unstable construct. Another explanation 


\section{PERSONALITY IN SITUATIONS}

would be that situation perception is stronger affected by momentary states, such as affect, and that even the responses to a vignette-based questionnaire such as the B5PS are subjected to this influence. This effect has already been shown for in situ situation perception (Horstmann \& Ziegler, 2018; Parrigon et al., 2017; Sherman et al., 2015; Wilson, Thompson, \& Vazire, 2016), but it has yet to be examined if this is also true for situation perception as a trait. Importantly though, empirical support for the temporal and cross-situation stability of the Situation Five scores was found which is a necessary condition when considering situation perception as a personality trait. This in itself is an important extension of the current status of research on situation perception. Clearly, this has potential implications for clinical psychology in particular, as we will elaborate below.

\section{Validity.}

Convergent and discriminant validity - Big Five. The convergent validity of the Big Five scores overall was good when compared with typical convergent correlations for Big Five measures (Pace \& Brannick, 2010). It has to be noted that the facets of the B5PS did not reflect the facet structure suggested by Costa and McCrae as is the case for the BFSI. Such differences in test family have been shown to be important factors lowering convergent validity (Miller, Gaughan, Maples, \& Price, 2011). Further, the discriminant validities of the Big Five scores were good. Although some domains (e.g., Openness and Extraversion, Conscientiousness and Extraversion, or Extraversion and Agreeableness) were substantially correlated, were not higher than the convergent correlations.

Convergent and discriminant validity - Situation Five. The discriminant validity of the Situation Five can be considered satisfactory with regard to Big Five scores. However, the correlations among the Situation Five scores were, in some cases, rather high (see Table E, 


\section{PERSONALITY IN SITUATIONS}

OSM). These correlations could be modeled using higher order factors. As we have mentioned earlier, other measures of situation perception show similar correlations among their scores (Brown et al., 2015; Parrigon et al., 2017; Rauthmann \& Sherman, 2016). First, measures of situation perception and measures of in situ behavior usually display a positive manifold (Baird, Le, \& Lucas, 2006), and situation perception measures are not orthogonal. It is an unresolved question, however, why this is the case: If a situation is assessed, it may simply be the case that participants are not able to distinguish sufficiently between situation aspects, and rather evaluate situations on a broader, more abstract level. Given that the Situation Five were assessed over many different situations, it may also be the case that momentary aspects of the person influenced the judgement. Indeed, the adjectives from the Situation Five were previously shown to correlate with measures of affect (Horstmann \& Ziegler, 2018).

At the time of data collections, no other measure for situation perception was readily available (Horstmann, Rauthmann, et al., 2018), and so far, no other measure of trait situation perception exists. However, previous research showed that the adjectives extracted for the Situation Five align with some of the DIAMONDS (Rauthmann et al., 2014) dimensions, further supporting construct validity of the test scores (Horstmann, Rauthmann, et al., 2018; Horstmann \& Ziegler, 2018; Rauthmann \& Sherman, 2018).

The Situation Five additionally showed good discriminant validities with the Big Five scores from the BFSI. Although some correlations were rather high ( $\sim 40)$, the Situation Five could still be considered independent constructs. This is comparable to other findings that demonstrated a correlation between situation perception and personality trait scores (Rauthmann, Sherman, Nave, et al., 2015; Sherman, Nave, \& Funder, 2013; Sherman et al., 2015). Personality may therefore be involved in shaping situation perceptions (Rauthmann, Sherman, \& Funder, 2015). 


\section{PERSONALITY IN SITUATIONS}

Test-criterion correlations. The main purpose for the construction of an assessment tool of situation perception in an occupational context was the prediction of work-related outcomes. Work-engagement and its three subscale scores were used as outcomes for an initial validation, and the results show that the Situation Five scores explain significant variance in all UWES scores, whereas the Big Five did not. This is in line with models of job engagement, such as the Job-Demand-Control-(Support) model (Johnson \& Hall, 1988; Karasek, 1979). A general tendency to interpret situations and perceive their demands, which can directly reflect one's available resources in this situation, could be more specific for the prediction of job-related behavior than personality scores. Although this would need further specific validation (i.e., are situation perceptions correlated with available resources or the lack thereof?), it could be the stepping-stone for future research.

Additionally, earlier studies also reported very small correlations between the Big Five and work engagement (Kim, Shin, \& Swanger, 2009). Moreover, it needs to be kept in mind that the factor scores used here were controlled for common method variance thereby also correcting test criterion correlations inflated by such variance sources.

With regard to the Situation Five, these results underscore that situation perception scores, assessed across a set of hypothetical situations in an occupational context, are a valid and so far unrecognized predictor for work-engagement. These initial results are encouraging and stress the importance of that construct. Moreover, the criterion chosen is of relevance for the clinical context just like the evidence for the feasibility of a combined measure for situation perception and personality traits is.

\section{Overall Discussion}

\section{Theoretical Implications - What is the Construct being measured?}




\section{PERSONALITY IN SITUATIONS}

The theoretical implications of these findings are manifold. First and most important, we demonstrate that situation perception has a stable trait component: The perception of a fixed set of situations is not only stable, but also predicts relevant outcomes in a work-related context. Similarly, Sherman and colleagues (2015) previously reported effects of trait-like situation perception on behavior in daily life. Dimensions of situation perception should thus be considered as a construct that enrich the nomological net of personality traits and allow predicting additional variance in behavior and other outcomes.

Second, the assessment of situation perception as a trait is possible and feasible. One argument against the use of situations in personality research was that considering only the situation would allow to only make point predictions, or in other words explanations of behavior in that very same situation (Hogan, 2009). Assessing situation perception as a personality trait allows predicting behavior across situations and thereby overcomes this strong criticism.

\section{Applied Contexts - What is the intended use of the measure?}

The first implication for an applied context is that situation perception could be considered for selection and training procedures in an occupational setting (Lievens, 2017). Situation perception might serve as an additional predictor and thus selection criterion, supporting the evidence presented by Rockstuhl and colleagues (Rockstuhl et al., 2015).

Second, situation perception and the measurement thereof are suitable tools for clinical psychology. As stated earlier, work-engagement is closely tied to clinically relevant outcomes such as burn-out or depression (Schaufeli \& Bakker, 2004; Schaufeli, Salanova, Gon Alez-ro, \& Bakker, 2002). Assessing a person's general perception of situations can therefore be used as an outset for intervention or even therapy. If the Situation Five indeed reflected the perceived availability of job-resources or demands, and this perception then caused burnout, situation 


\section{PERSONALITY IN SITUATIONS}

perception could be a link between the two. Situation perception of in situ ratings in specific situations might further be used to shape and change environments such that they are evaluated more positively by their perceivers. This has so far not been examined or considered but may be a valuable avenue for further research.

The B5PS can furthermore be understood as a proof of concept and blueprint for the creation of assessment tools for situation-contingent perception and behavior. For example, the situation vignettes used could easily be replaced with critical incidents provided by clinicians or therapists of their patients' lives. Such a situation rating tool for clinically relevant situations may suit a larger audience of participants, not only in an occupational setting. The availability of situations that have received a normative rating can shed new lights on the processes involved in mental malfunctions and the occurrence of pathological behavior.

\section{Limitations}

Model Fit. The model fit of the presented measurement models of the Situation Five in the B5PS is not optimal. Especially the low CFI might be cause for concern. As mentioned above, this is rather typical for personality measures (Hopwood \& Donnellan, 2010). The CFI is indicative of unexplained unique variance in manifest variables, and as such, it has to be concluded that the ratings in situation perception cannot completely be explained by situation perception as a trait (Horstmann, Ziegler, et al., 2018). The higher order factor models for the Situation Five were furthermore modeled using item parcels. This approach allows testing the structure of the Situation Five (Study 2 and Study 3), without having to sample too many participants. At the same time, model misfit can be masked using item-parcels (Little et al., 2002). Although the higher order factor structure of the Situation Five could be confirmed across two independent samples and using a different set of stimuli, these results must be interpreted 


\section{PERSONALITY IN SITUATIONS}

cautiously. Most importantly, it should not be concluded that situations are primarily perceived on two dimensions only.

Population. One limitation of the assessment tool is that it only refers to white-collar workers their occupational environments. Other contexts, such as manual work, were not considered and the generalizability to these contexts may therefore be limited. Furthermore, the construction of the taxonomy initially relied on students who chose to report a self-selected situation from their previous day. Although this may lead to higher ecological validity (i.e., only situations are sampled that are commonly experienced), other, more extreme situations might be overlooked: The structure of situations that are rarely experienced during everyday life (e.g., a burning house, a surgery, a funeral) could differ from everyday self-selected situations, and the Situation Five taxonomy might therefore not be applicable to such contexts.

\section{General Conclusion}

The current research article contributes several aspects to the research on person-situation transactions. First, the development of a new set of dimensions of situation characteristics provides further insight into the development of the structure and content of situations. Situation research may bring forward other taxonomies, and linking different taxonomies together examining their convergent and discriminant validity, which might be different on a trait and state level (Rauthmann, Horstmann, \& Sherman, 2018), is the next task at hand.

Second, the B5PS is a measurement tool that allows assessing trait situation perception and Big Five personality scores of a person simultaneously in a reliable and valid form. This demonstrates that valid results based on ratings of vignettes can be obtained (Ziegler \& Ziegler, 2015). Besides the here shown application in organizational settings, this seems especially 


\section{PERSONALITY IN SITUATIONS}

promising in clinical settings. A measure capturing situation perceptions and manifestations of pathological traits might contribute important insights for diagnoses and therapies.

Third, our research shows that situation perception has a stable trait component. Applications of other situation perception taxonomies could benefit from the recognition of these trait components of situation perceptions. Situation research has taken a new turn in the last years; however, the current results and theoretical developments clearly indicate that situation research still holds many secrets. 


\section{PERSONALITY IN SITUATIONS}

Allport, G. W., \& Odbert, H. S. (1936). Trait-names: A psycho-lexical study. Psychological Monographs, 47, i-171.

Arendasy, M. (2011). Big-Five Struktur Inventar (BFSI). Mödling: Schuhfried GmbH.

Bäckström, M. (2007). Higher-Order Factors in a Five-Factor Personality Inventory and its Relation to Social Desirability. European Journal of Psychological Assessment, 23, 63-70.

Bäckström, M., Björklund, F., \& Larsson, M. R. (2009). Five-factor inventories have a major general factor related to social desirability which can be reduced by framing items neutrally. Journal of Research in Personality, 43, 335-344.

Baird, B. M., Le, K., \& Lucas, R. E. (2006). On the nature of intraindividual personality variability: Reliability, validity, and associations with well-being. Journal of Personality and Social Psychology, 90, 512-527.

Barrick, M. R., Mount, M. K., \& Judge, T. A. (2001). Personality and Performance at the Beginning of the New Millennium: What Do We Know and Where Do We Go Next? International Journal of Selection and Assessment, 9, 9-30.

Biderman, M. D., Nguyen, N. T., Cunningham, C. J. L., \& Ghorbani, N. (2011). The ubiquity of common method variance: The case of the Big Five. Journal of Research in Personality, 45, $417-429$.

Brown, N. A., Neel, R., \& Sherman, R. A. (2015). Measuring the Evolutionarily Important Goals of Situations: Situational Affordances for Adaptive Problems. Evolutionary Psychology, 13, $1-15$.

Burns, M. N., Begale, M., Duffecy, J., Gergle, D., Karr, C. J., Giangrande, E., \& Mohr, D. C. (2011). Harnessing Context Sensing to Develop a Mobile Intervention for Depression. Journal of Medical Internet Research, 13, e55. 


\section{PERSONALITY IN SITUATIONS}

Chen, J., Furukawa, T. A., Nakano, Y., Ietsugu, T., Ogawa, S., Funayama, T., ... Rapee, R. M. (2010). Video feedback with peer ratings in naturalistic anxiety-provoking situations for social anxiety disorder: Preliminary report. Journal of Behavior Therapy and Experimental Psychiatry, 41, 6-10.

Costa, P. T., \& McCrae, R. R. (1995). Domains and Facets: Hierarchical Personality Assessment Using the Revised NEO Personality Inventory. Journal of Personality Assessment, 64, $21-$ 50.

Deary, I. (2009). The trait approach to personality. In G. Matthews \& P. J. Corr (Eds.), The Cambridge handbook of personality psychology. (pp. 89-109). Cambridge: Cambridge University Press.

Dudenredaktion. (2006). Die deutsche Rechtschreibung. Bd. 1. 24. völlig neu bearb. u. erweiterte Auflage. Mannheim: Dudenverlag.

E., R., \& Diener, E. (2009). Personality and Subjective Well-Being. In E. Diener (Ed.), The Science of Well-Being: The Collected Works of Ed Diener (pp. 75-102). Dordrecht: Springer Netherlands.

Edwards, J., \& Templeton, A. (2005). The structure of perceived qualities of situations. European Journal of Social Psycholgy, 723, 705-723.

Gerpott, F. H., Balliet, D., Columbus, S., Molho, C., \& de Vries, R. E. (2017). How Do People Think About Interdependence? A Multidimensional Model of Subjective Outcome Interdependence. Journal of Personality and Social Psychology.

Geukes, K., Nestler, S., Hutteman, R., Küfner, A. C. P., \& Back, M. D. (2016). Trait personality and state variability: Predicting individual differences in within- and cross-context fluctuations in affect, self-evaluations, and behavior in everyday life. Journal of Research in 


\section{PERSONALITY IN SITUATIONS}

\section{Personality.}

Goldberg, L. R. (1990). An alternative "description of personality": the big-five factor structure. Journal of Personality and Social Psychology, 59, 1216-1229.

Greiff, S., \& Heene, M. (2017). Why Psychological Assessment Needs to Start Worrying About Model Fit. European Journal of Psychological Assessment, 33, 313-317.

Heene, M., Hilbert, S., Draxler, C., Ziegler, M., \& Bühner, M. (2011). Masking misfit in confirmatory factor analysis by increasing unique variances: a cautionary note on the usefulness of cutoff values of fit indices. Psychological Methods, 16, 319-36.

Hogan, R. (2009). Much ado about nothing: The person-situation debate. Journal of Research in Personality, 43, 249.

Hopwood, C. J., \& Donnellan, M. B. (2010). How Should the Internal Structure of Personality Inventories Be Evaluated? Personality and Social Psychology Review, 14, 332-346.

Horstmann, K. T., Rauthmann, J. F., \& Sherman, R. A. (2018). Measurement of situational influences. In V. Zeigler-Hill \& T. K. Shackelford (Eds.), The SAGE Handbook of Personality and Individual Differences. SAGE Publications.

Horstmann, K. T., Ziegler, J., \& Ziegler, M. (2018). Assessment of Situational Perceptions: Measurement issues and a joint taxonomization of persons/situations. In D. C. Funder, J. F. Rauthmann, \& R. A. Sherman (Eds.), The Oxford Handbook of Psychological Situations. Oxford University Press.

Horstmann, K. T., \& Ziegler, M. (2016). Situational Perception: Its Theoretical Foundation, Assessment, and Links to Personality. In U. Kumar (Ed.), The Wiley Handbook of Personality Assessment (1st ed., pp. 31-43). Oxford: Wiley Blackwell.

Horstmann, K. T., \& Ziegler, M. (2018). Situational perception and affect: Barking up the wrong 


\section{PERSONALITY IN SITUATIONS}

tree? Personality and Individual Differences.

Hu, L., \& Bentler, P. M. (1999). Cutoff criteria for fit indexes in covariance structure analysis: Conventional criteria versus new alternatives. Structural Equation Modeling: A Multidisciplinary Journal, 6, 1-55.

IPIP. (2015). International Personality Item Pool: A scientific collaboratory for the development of advanced measures of personality traits and other individual differences. Retrieved from http://ipip.ori.org/

John, O., \& Srivastava, S. (1999). The Big Five trait taxonomy: History, measurement, and theoretical perspectives. In The Big Five Trait taxonomy: History, measurement, and theoretical perspectives (pp. 102-138).

Johnson, J. V, \& Hall, E. M. (1988). Job strain, work place social support, and cardiovascular disease: a cross-sectional study of a random sample of the Swedish working population. American Journal of Public Health, 78, 1336-1342.

Kanfer, F. H., \& Saslow, G. (1965). Behavioral Analysis: An alternative to diagnostic classification. Archives of General Psychiatry, 12, 529.

Karasek, R. A. (1979). Job Demands, Job Decision Latitude, and Mental Strain: Implications for Job Redesign. Administrative Science Quarterly, 24, 285.

Keller, M. C., \& Nesse, R. M. (2006). The evolutionary significance of depressive symptoms: Different adverse situations lead to different depressive symptom patterns. Journal of Personality and Social Psychology, 91, 316-330.

Kim, H. J., Shin, K. H., \& Swanger, N. (2009). Burnout and engagement: A comparative analysis using the Big Five personality dimensions. International Journal of Hospitality Management, 28, 96-104. 


\section{PERSONALITY IN SITUATIONS}

Klehe, U.-C., Kleinmann, M., Hartstein, T., Melchers, K. G., König, C. J., Heslin, P. A., \& Lievens, F. (2012). Responding to Personality Tests in a Selection Context: The Role of the Ability to Identify Criteria and the Ideal-Employee Factor. Human Performance, 25, 273302.

Kuppens, P. (2009). The legacy of the person-situation debate for understanding variability in emotional experience. Journal of Research in Personality, 43, 255-256.

Lewin, K. (1936). Principles of topological psychology. New York-London. New York: McGraw Hill.

Lievens, F. (2017). Assessing Personality-Situation Interplay in Personnel Selection: Toward More Integration into Personality Research. European Journal of Personality, 31, 424-440.

Little, T. D., Cunningham, W. a., Shahar, G., \& Widaman, K. F. (2002). To Parcel or Not to Parcel: Exploring the Question, Weighing the Merits. Structural Equation Modeling: A Multidisciplinary Journal, 9, 151-173.

MacCann, C., Danay, E., Ziegler, M., \& Roberts, R. (2011). A comprehensive facet structure for agreeableness/extraversion. Paper Presented at the ISSID, London.

Mauno, S., Kinnunen, U., \& Ruokolainen, M. (2007). Job demands and resources as antecedents of work engagement: A longitudinal study. Journal of Vocational Behavior, 70, 149-171.

McDaniel, M. A., Morgeson, F. P., Finnegan, E. B., Campion, M. A., \& Braverman, E. P. (2001). Use of situational judgment tests to predict job performance: A clarification of the literature. Journal of Applied Psychology, 86, 730-740.

Miller, J. D., Gaughan, E. T., Maples, J., \& Price, J. (2011). A Comparison of Agreeableness Scores From the Big Five Inventory and the NEO PI-R: Consequences for the Study of Narcissism and Psychopathy. Assessment, 18, 335-339. 


\section{PERSONALITY IN SITUATIONS}

Mischel, W., \& Shoda, Y. (1995). A cognitive-affective system theory of personality: Reconceptualizing situations, dispositions, dynamics, and invariance in personality structure. Psychological Review, 102, 246-68.

Mount, M. K., Barrick, M. R., Scullen, S. M., \& Rounds, J. (2005). Higher-Order Dimensions of the Big Five Personality Traits and the Big Sic Vocational Interest Types. Personnel Psychology, 58, 447-478.

Muthén, L. K., \& Muthen, B. O. (2015). Mplus.

Oshio, A., Abe, S., Cutrone, P., \& Gosling, S. D. (2014). Further Validity of the Japanese Version of the Ten Item Personality Inventory (TIPI-J). Journal of Individual Differences, $35,236-244$.

Oud, J. H. L., Voelkle, M. C., \& Driver, C. C. (2017). SEM Based CARMA Time Series Modeling for Arbitrary N. Multivariate Behavioral Research, 1-21.

Ozer, D. J., \& Benet-Martínez, V. (2006). Personality and the prediction of consequential outcomes. Annual Review of Psychology, 57, 401-421.

Pace, V. L., \& Brannick, M. T. (2010). How similar are personality scales of the "same" construct? A meta-analytic investigation. Personality and Individual Differences, 49, 669676.

Parrigon, S. (2017). The lexical approach to situations: History, theory, and practice. In The Oxford Handbook of Psychological Situations. Oxford University Press.

Parrigon, S., Woo, S. E., Tay, L., \& Wang, T. (2017). CAPTION-ing the situation: A lexicallyderived taxonomy of psychological situation characteristics. Journal of Personality and Social Psychology, 112, 642-681.

R Core Team. (2016). $R$ : A language and environment for statistical computing. $R$ Foundation 


\section{PERSONALITY IN SITUATIONS}

for Statistical Computing, Vienna, Austria. http://www.R-project.org/.

Rauthmann, J. F. (2012). You Say the Party is Dull, I Say It is Lively: A Componential Approach to How Situations Are Perceived to Disentangle Perceiver, Situation, and Perceiver x Situation Variance. Social Psychological and Personality Science, 3, 519-528.

Rauthmann, J. F., Gallardo-Pujol, D., Guillaume, E. M., Todd, E., Nave, C. S., Sherman, R. A., ... Funder, D. C. (2014). The situational eight DIAMONDS: A taxonomy of major dimensions of situation characteristics. Journal of Personality and Social Psychology, 107, $677-718$.

Rauthmann, J. F., \& Horstmann, K. T. (2017). Overview of Situation Characteristic Taxonomies.

Rauthmann, J. F., Horstmann, K. T., \& Sherman, R. A. (2018). Do self-reported traits and aggregated states capture the same thing? A nomological perspective on trait-state homomorphy. Social Psychological and Personality Science.

Rauthmann, J. F., \& Sherman, R. A. (2016). Measuring the Situational Eight DIAMONDS Characteristics of Situations. European Journal of Psychological Assessment, 32, 155-164.

Rauthmann, J. F., \& Sherman, R. A. (2018). The description of situations: Towards replicable domains of psychological situation characteristics. Journal of Personality and Social Psychology.

Rauthmann, J. F., Sherman, R. A., \& Funder, D. C. (2015). Principles of Situation Research: Towards a Better Understanding of Psychological Situations. European Journal of Personality, 29, 363-381.

Rauthmann, J. F., Sherman, R. A., Nave, C. S., \& Funder, D. C. (2015). Personality-driven situation experience, contact, and construal: How people's personality traits predict characteristics of their situations in daily life. Journal of Research in Personality, 55, 98 


\section{PERSONALITY IN SITUATIONS}

111.

Revelle, W. (2014). psych: Procedures for Psychological, Psychometric, and Personality Research. http://CRAN.R-project.org/package=psych Version = 1.4.5.

Rockstuhl, T., Ang, S., Ng, K.-Y., Lievens, F., \& Van Dyne, L. (2015). Putting judging situations into situational judgment tests: Evidence from intercultural multimedia SJTs. Journal of Applied Psychology, 100, 464-480.

Rosseel, Y. (2015). lavaan: Latent Variable Analysis.

Rubin, D. B. (1976). Inference and missing data. Biometrika, 63, 581-592.

Sander, D., Grandjean, D., \& Scherer, K. R. (2005). A systems approach to appraisal mechanisms in emotion. Neural Networks, 18, 317-352.

Schaufeli, W. B., \& Bakker, A. B. (2004). Job demands, job resources, and their relationship with burnout and engagement: a multi-sample study. Journal of Organizational Behavior, $25,293-315$.

Schaufeli, W. B., Salanova, M., Gon Alez-ro, V. A., \& Bakker, A. B. (2002). the Measurement of Engagement and Burnout: a Two Sample Confirmatory Factor Analytic Approach. Journal of Happiness Studies, 3, 71-92.

Schmidt, F. L., \& Hunter, J. E. (1998). The validity and utility of selection methods in personnel psychology: Practical and theoretical implications of 85 years of research findings. Psychological Bulletin, 124, 262-274.

Schmit, M. J., \& Ryan, A. M. (1993). The Big Five in personnel selection: Factor structure in applicant and nonapplicant populations. Journal of Applied Psychology, 78, 966-974.

Schwartz, G. E., \& Weinberger, D. A. (1980). Patterns of emotional responses to affective situations: Relations among happiness, sadness, anger, fear, depression, and anxiety. 


\section{PERSONALITY IN SITUATIONS}

\section{Motivation and Emotion, 4, 175-191.}

Seppälä, P., Mauno, S., Feldt, T., Hakanen, J., Kinnunen, U., Tolvanen, A., \& Schaufeli, W. (2009). The Construct Validity of the Utrecht Work Engagement Scale: Multisample and Longitudinal Evidence. Journal of Happiness Studies, 10, 459-481.

Shaffer, J. A., \& Postlethwaite, B. E. (2012). A Matter of Context: A Meta-Analytic Investigation of the Relative Validity of Contextualized and Noncontextualized Personality Measures. Personnel Psychology, 65, 445-494.

Sherman, R. A., Nave, C. S., \& Funder, D. C. (2013). Situational construal is related to personality and gender. Journal of Research in Personality, 47, 1-14.

Sherman, R. A., Rauthmann, J. F., Brown, N. A., Serfass, D. G., \& Jones, A. B. (2015). The independent effects of personality and situations on real-time expressions of behavior and emotion. Journal of Personality and Social Psychology, 109, 872-888.

Tett, R. P., \& Burnett, D. D. (2003). A personality trait-based interactionist model of job performance. Journal of Applied Psychology, 88, 500-517.

Tett, R. P., \& Guterman, H. A. (2000). Situation trait relevance, trait expression, and crosssituational consistency: Testing a principle of trait activation. Journal of Research in Personality, 34, 397-423.

Thalmayer, A. G., \& Saucier, G. (2014). The Questionnaire Big Six in 26 Nations: Developing Cross-Culturally Applicable Big Six, Big Five and Big Two Inventories. European Journal of Personality, 28, 482-496.

Thomas, K. M., Yalch, M. M., Krueger, R. F., Wright, A. G. C., Markon, K. E., \& Hopwood, C. J. (2013). The Convergent Structure of DSM-5 Personality Trait Facets and Five-Factor Model Trait Domains. Assessment, 20, 308-311. 


\section{PERSONALITY IN SITUATIONS}

Van Heck, G. L. (1984). The construction of a general taxonomy of situations. In H. Bonarius, G. L. Van Heck, \& N. Smid (Eds.), Personlity psychology in Europe: Theoretical and empirical developments (pp. 149-164). Lisse, The Netherlands: Swets and Zeitlinger.

Van Heck, G. L. (1989). Situation concepts: Definitions and classification. Personality and Environment: Assessment of Human Adaptation, 53-69.

Wilson, R. E., Thompson, R. J., \& Vazire, S. (2016). Are fluctuations in personality states more than fluctuations in affect? Journal of Research in Personality.

Yang, Y., Read, S. J., \& Miller, L. C. (2006). A taxonomy of situations from Chinese idioms. Journal of Research in Personality, 40, 750-778.

Ziegler, M. (2014a). Comments on Item Selection Procedures. European Journal of Psychological Assessment, 30, 1-2.

Ziegler, M. (2014b). Stop and State Your Intentions! European Journal of Psychological Assessment, 30, 239-242.

Ziegler, M., \& Buehner, M. (2009). Modeling Socially Desirable Responding and Its Effects. Educational and Psychological Measurement, 69, 548-565.

Ziegler, M., Cengia, A., \& Roberts, R. (in prep.). A facetted Big Five measure: Construction, evaluation and measurement invariance across German and American samples.

Ziegler, M., \& Horstmann, K. (2015). Discovering the Second Side of the Coin. European Journal of Psychological Assessment, 31, 69-74.

Ziegler, M., \& Ziegler, J. (2015). Better understanding of psychological situations: opportunities and challenges for psychological assessment. European Journal of Personality, 29, 418419. 


\section{PERSONALITY IN SITUATIONS}

Table 1

Model-Fits for the Situation Five and Big Five Models

\begin{tabular}{|c|c|c|c|c|c|c|c|c|}
\hline \multirow[b]{2}{*}{ Situation Five } & \multicolumn{8}{|c|}{ Study 2} \\
\hline & $X^{2}$ & $p$ & $d f$ & CFI & TLI & RMSEA & SRMR & Estimator \\
\hline $\begin{array}{l}\text { Outcome- } \\
\text { Expectancy }\end{array}$ & 124.44 & $<.001$ & 27 & .98 & .97 & $.097[.080 ; .114]$ & .04 & WLSMV \\
\hline $\begin{array}{l}\text { Briskness } \\
\text { Psych. and Phys. }\end{array}$ & 107.95 & $<.001$ & 20 & .96 & .94 & $.107[.087 ; .127]$ & .06 & WLSMV \\
\hline Load & 116.99 & $<.001$ & 27 & .98 & .98 & $.093[.076 ; .111]$ & .04 & WLSMV \\
\hline Lack of Stimuli & 86.50 & $<.001$ & 27 & .99 & .99 & $.076[.058 ; .094]$ & .03 & WLSMV \\
\hline Cognitive Load* & 70.94 & $<.001$ & 16 & .98 & .97 & $.094[.073 ; .117]$ & .05 & WLSMV \\
\hline & & & & & Stu & & & \\
\hline Situation Five & $X^{2}$ & $p$ & $d f$ & CFI & TLI & RMSEA & SRMR & Estimator \\
\hline $\begin{array}{l}\text { Outcome- } \\
\text { Expectancy }\end{array}$ & 3424.81 & $<.001$ & 819 & .74 & .72 & $.090[.086 ; .093]$ & .09 & WLSMV \\
\hline $\begin{array}{l}\text { Briskness } \\
\text { Psych. and Phys. }\end{array}$ & 3920.56 & $<.001$ & 860 & .67 & .66 & $.095[.092 ; .098]$ & .10 & WLSMV \\
\hline Load & 2270.24 & $<.001$ & 819 & .88 & .88 & $.067[.064 ; .070]$ & .07 & WLSMV \\
\hline Lack of Stimuli & 2707.28 & $<.001$ & 819 & .71 & .71 & $.076[.073 ; .079]$ & .09 & WLSMV \\
\hline Cognitive Load & 3107.94 & $<.001$ & 629 & .58 & .55 & $.100[.096 ; .103]$ & .11 & WLSMV \\
\hline Big Five & $X^{2}$ & $p$ & $d f$ & CFI & TLI & RMSEA & SRMR & Estimator \\
\hline Emotional Stability & 42.74 & $<.001$ & 14 & .96 & .94 & $.072[.050 ; .095]$ & .04 & MLR \\
\hline Extraversion & 104.60 & $<.001$ & 25 & .91 & .88 & $.090[.074 ; .106]$ & .05 & MLR \\
\hline $\begin{array}{l}\text { Openness/Flexibility } \\
\text { Agreeableness/Team }\end{array}$ & 59.90 & $<.001$ & 27 & .95 & .93 & $.055[.039 ; .072]$ & .04 & MLR \\
\hline -Orientation & 48.56 & $<.001$ & 18 & .89 & .83 & $.065[.045 ; .086]$ & .05 & MLR \\
\hline Conscientiousness & 113.69 & $<.001$ & 27 & .88 & .84 & $.090[.075 ; .105]$ & .06 & MLR \\
\hline
\end{tabular}

Note. $N=387$ (Study 2), $N=398$ (Study 3).

The Situation Five were modeled on the item level in both studies, whereas the Big Five were modeled on the facet level. 


\section{PERSONALITY IN SITUATIONS}

Table 2

Bivariate Correlations between the Big Five (BFSI) and the Big Five and Situation Five Scores

\begin{tabular}{|c|c|c|c|c|c|}
\hline \multirow[b]{2}{*}{ Situation Five } & \multicolumn{5}{|c|}{ BFSI Dimensions } \\
\hline & ES & $E$ & $\mathrm{O}$ & $\mathrm{A}$ & $\mathrm{C}$ \\
\hline Outcome-Expectancy & $.35 * * *$ & $.43 * * *$ & $.37 * * *$ & $.15^{* *}$ & $.35 * * *$ \\
\hline Briskness & $.13 *$ & $.25 * * *$ & $.31 * * *$ & $.17 * * *$ & $.23 * * *$ \\
\hline Psych. and Phys. Load & $-.46^{* * *}$ & $-.23 * * *$ & $-.12 *$ & -.06 & $-.13 *$ \\
\hline Lack of Stimuli & $-.25^{* * *}$ & $-.11 *$ & -.08 & $-.17 * * *$ & $-.20 * * *$ \\
\hline Cognitive Load & -.04 & .09 & $.13^{* *}$ & $.11^{*}$ & $.24 * * *$ \\
\hline Big Five & ES & E & $\mathrm{O}$ & $\mathrm{A}$ & $\mathrm{C}$ \\
\hline Emotional Stability & $.42 * * *$ & $.11 *$ & -.08 & -.07 & -.03 \\
\hline Extraversion & .08 & $.40 * * *$ & $.16^{* *}$ & .07 & $-.22 * * *$ \\
\hline Openness/Flexibility & $-.24 * * *$ & .01 & $.35 * * *$ & .05 & -.02 \\
\hline $\begin{array}{l}\text { Agreeableness/ } \\
\text { Team-Orientation }\end{array}$ & -.03 & $-.17 * *$ & -.04 & $.28 * * *$ & .05 \\
\hline Conscientiousness & $-.18 * * *$ & $-.13 *$ & -.03 & -.01 & $.28 * * *$ \\
\hline
\end{tabular}

Note. $\mathrm{ES}=$ Emotional Stability; $\mathrm{E}=$ Extraversion; $\mathrm{O}=$ Openness; $\mathrm{A}=$ Agreeableness, $\mathrm{C}=$ Conscientiousness; $N=387$ of the 398 participants completed the BFSI. Correlations in bold are convergent correlations between Big Five scores from different questionnaires. 